\title{
OPINION
}

\section{Measure methane to quantify the oil spill}

\author{
Plumes of dissolved gas could be used to determine how much oil has leaked into the Gulf of Mexico, \\ says David Valentine - if the studies are done soon.
}

A s oil continues to gush into the Gulf of Mexico in the wake of the Deepwater Horizon rig explosion, the question remains: how big an environmental disaster is this? Observing the surface slick and the deepsea leak are of limited use in this situation. A more effective approach might be to quantify the leaked methane gas dissolved in the water something that hasn't been done before to assess the size of a spill, but that in theory should work well. Although researchers are already measuring methane in some Gulf water samples, a larger-scale project is urgently required to map the methane plumes in real time.

The 20 April blowout was caused by the violent eruption of pressurized methane gas from a well about 1.5 kilometres below sea level. A series of explosions sank the rig, rupturing the riser pipe that ran between the rig and the oil well. This left oil gushing from multiple sources along the riser, which is now lying on the sea floor, creating a massive oil slick.

Knowing how much oil has been spilled will be useful for comparing one spill to another, predicting ecological effects, assessing the efficacy of remediation measures and tracking the fate of dispersed oil. Moreover, the US Oil Pollution Act of 1990 requires the completion of a natural-resource damage assessment to determine liability, and the quantity spilled is a factor in damage assessment models.

Federal agencies are putting the release rate at 5,000 barrels per day. Publicized estimates have ranged from 1,000 to 100,000 barrels per day, with little detail available about the methods being used. Visual observations of leakage from the ruptured pipe are unreliable because of the turbulent flow and the uncertain water content of the oil-water-gas mixture. Spot measurements of

\section{"Knowing how much oil has been spilled will help to determine liability."}

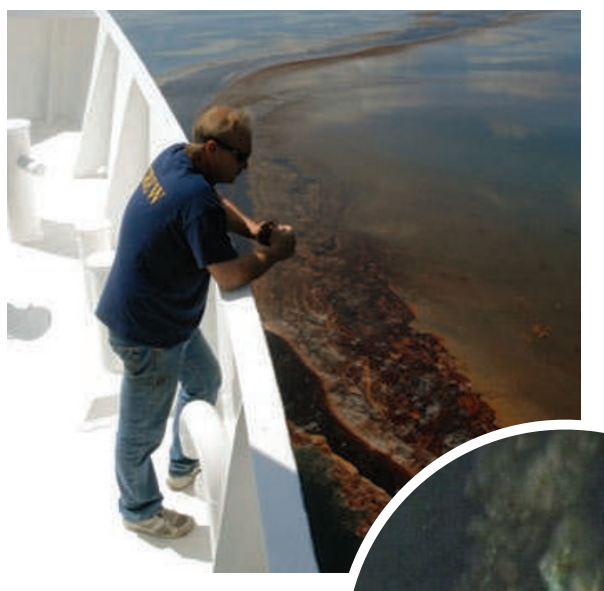

Dissolved methane could help quantify Deepwater Horizon leakage (inset).

plumes of dissolved methane emanating from the site. Methane gas is the most abundant compound in the spill, constituting approximately $40 \%$ of the leaking petroleum by mass, according to energy company BP, which controls the reservoir. Although methane from surface-vessel spills or shallow-water blowouts escapes into the air, I expect that the vast majority of methane making the long trip to the sea surface from a deep water spill would dissolve. Unlike oil, methane dissolves uniformly in seawater. And the tools are available to measure it accurately and sensitively.

Assuming a flow rate of 5,000 barrels per day and methane-in-oil content of 80 cubic metres per barrel (at standard temperature and pressure), about 7,500 tonnes of methane were released to the Gulf the flux at any given moment can't be scaled up reliably, because the flow may not be constant. Satellite photos and boat measurements help to assess the distribution and thickness of the surface slick, but these measures are also highly variable with time, place, weather conditions and dispersant application. In what is likely to be the worst oil spill in US history, a more accurate way to estimate the spill's magnitude is needed.

A promising technique is to measure the of Mexico during the first 27 days of the spill. This is enough to, for example, triple normal background methane concentrations in a volume of water 5,000 square kilometres at the surface and 1.5 kilometres deep. In reality, it is probable that there will be higher-concentration plumes than that, stretching tens or hundreds of kilometres from the sources.

This approach is not immune to uncertainties. Some methane will be lost to bacterial metabolism and perhaps to the air. Background concentrations will fluctuate because of processes such as natural methane seepage from the sea floor. However, these sources of error can be reduced through other methane measurements, including isotopic composition, oxidation rates in the water, partitioning into oil and concentrations in the air. The biggest difficulty is likely to be locating and measuring all major plumes before they disperse.

The first research ship on the scene has made great efforts to document the spill (see Nature $465,274-275 ; 2010)$, but more work is needed. In June, we should aim to get to grips with the size and shape of the methane plumes by tracking water flow with 'drifting profiling floats' and through further spot analyses. This should be followed by a thorough two-vessel expedition, to ensure that the plumes are quantified as comprehensively as possible. Although this could not realistically identify all of the released methane, it would at least put a lower bound on the total amount of spilled oil. Measures of methane-plume movement could also be used to estimate the rate of the spill.

The US academic research fleet alone has a dozen vessels capable of such work, at costs of probably a few million dollars or less. Systems are available for measuring methane concentration in real time from overboard instruments, allowing plumes to be mapped. Spot observations from water samples would provide a higher-accuracy reference for these measurements. Such a project would be the best chance of quantifying the spill, and would prove an excellent opportunity for scientists to test and calibrate methane-detection systems.

Capitalizing on this idea requires immediate action. I am calling for a concerted community effort, with appropriate commitment from the US government, the trustees of the Deepwater Horizon incident and BP. The likely rewards far exceed the costs.

David Valentine is in the Department of Earth Science and the Marine Science Institute, University of California, Santa Barbara, California 93106, USA.

e-mail: valentine@geol.ucsb.edu

For updates, or to comment, see the online version of this story at go.nature.com/hs2nWG. 